\title{
In Different Voices: The Views of People with Disabilities about Return of Results from Precision Medicine Research
}

\author{
Maya Sabatello ${ }^{a}$ Yuan Zhang ${ }^{b}$ Ying Chen ${ }^{c}$ Paul S. Appelbaum ${ }^{d}$ \\ ${ }^{a}$ Center for Research on Ethical, Legal and Social Implications of Psychiatric, Neurologic and Behavioral Genetics, \\ Department of Psychiatry, Columbia University, New York, NY, USA; ${ }^{b}$ Department of Biostatistics, Mailman School \\ of Public Health, Columbia University, New York, NY, USA; ${ }^{C}$ Research Scientist and Biostatistician, New York \\ State Psychiatric Institute, New York, NY, USA; ${ }^{\text {d} C e n t e r ~ f o r ~ R e s e a r c h ~ o n ~ E t h i c a l, ~ L e g a l ~ a n d ~ S o c i a l ~ I m p l i c a t i o n s ~ o f ~}$ \\ Psychiatric, Neurologic and Behavioral Genetics, Department of Psychiatry, Columbia University, New York, NY, USA
}

\section{Keywords}

Disability · Precision medicine research · Return of results ·

Medicalization · Marginalization

\begin{abstract}
Purpose: Returning genetic results to research participants is gaining momentum in the USA. It is believed to be an important step in exploring the impact of efforts to translate findings from research to bedside and public health benefits. Some also hope that this practice will incentivize research participation, especially among people from historically marginalized communities who are commonly underrepresented in research. However, research participants' interest in receiving nongenomic medical and nonmedical results that may emerge from precision medicine research (PMR) is understudied and no study to date has explored the views of people with disabilities about return of genomic and nongenomic results from PMR. Methods: In a national online survey of people with disabilities, participants were queried about their interest in receiving biological, environmental, and lifestyle results from PMR $(n=1,294)$. Analyses describe findings for all of the participants and comparisons for key demographic characteristics and disability subgroups. $\boldsymbol{R e}$ -
\end{abstract}

sults: The participants expressed high interest in biological and health-related results and less interest in other findings. However, the interest among the study participants was lower than that found in comparable studies of the general population. Moreover, this interest varied significantly across gender, race/ethnicity, and disability subgroups. Possible reasons for these differences are discussed. Conclusion: Insofar as return of results from PMR may impact translational efforts, it is important to better understand the role of sociomedical marginalization in decisions about return of results from PMR and to develop strategies to address existing barriers.

(c) 2020 S. Karger AG, Basel

\section{Introduction}

Over the last decade, considerable research has addressed challenges relating to the return of genomic results to research participants. What to return, to whom, who decides, and what impact such data might have on the psychosocial wellbeing of research participants [1] have received growing national and international attention. Although the answers to these questions vary among

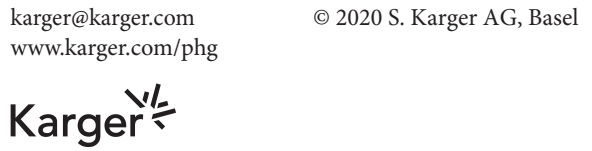

Dr. M. Sabatello

Center for Research on Ethical, Legal \& Social Implications of Psychiatric, Neurologic \& Behavioral Genetics, Department of Psychiatry, New York State Psychiatric Institute 1051 Riverside Dr., Unit 122, New York, NY 10032 (USA) ms4075@columbia.edu 
public [2-4] and scientific [5-8] stakeholders, studies indicate that many research participants $[4,9-11]$ express interest in receiving genetic results, especially results that show an increased risk for preventable or treatable diseases, adverse responses to medication, and carrier status with reproductive implications. These findings play a role in the increasingly common practice of offering return of genetic results to research participants and were endorsed by the national precision medicine research (PMR) initiative, i.e., the All of Us Research Program, which promises that cohort participants will have access to their own data and analyzed results $[12,13]$.

Little is known about the views of people with disabilities on return of results (RoR) from genetic research. However, emerging studies in other historically marginalized groups suggest that differences in views may exist. For instance, studies have found that women are more likely than men to express interest in genetic testing [14] and that views about RoR may be impacted by race and ethnicity. A focus group study, e.g., found that African Americans may be less inclined to receive genomic results compared to non-African Americans [15], and another large study of families with a Mendelian disease found that participants of non-European ancestry were more likely than participants of European ancestry to decline all results [16]. A recent study further found that educational attainment affected responses, such that participants with a high school diploma or less viewed genetic risk of disease to be the least valuable data, compared to participants with a higher educational attainment, who viewed such data as most valuable [17].

Although these initial studies are informative, the views of people with disabilities about return of genetic results may be markedly different than those of research participants from the general public or other underrepresented communities. As a group, people with disabilities comprise the largest health disparities group in the USA [18] and experience unique disadvantages as compared to members of the general population [19]. People with disabilities from other minority groups may experience "othering" within both the general population and their gender, racial, and ethnic groups [20], which may impact their views on the desirability of receiving genetic results. Moreover, the perspectives of people with disabilities may be intertwined with other objectives relating to their conditions, such as interest in finding treatments for their condition (e.g., among patients with inherited vision disabilities [21]) or, conversely, worries about the characterization of their conditions as deficits and the promotion of efforts to find cures for them (e.g., among members of the Deaf and Autistic/Neuro-diverse communities [22, 23]). Insofar as return of genetic results from research may incentivize participation in research [4] and a step towards improving one's health trajectory [12], it is important to explore whether this approach resonates with people with disabilities.

The rise of PMR adds another level of complexity to this discussion. Precision medicine is the newly emerging approach to healthcare, aimed at tailoring prevention, diagnosis, and treatment options to individual biological, environmental, and lifestyle data [24-26]. Accordingly, data collected from, analyzed, and possibly returned to participants in PMR may include clinical genomic results, ancestry genetic results, other laboratory results, dietary analysis, and findings about residential environmental degradation. However, research on the views of research participants about the return of these other types of results is limited and studies focusing on people with disabilities do not currently exist.

We report findings from a national study that explored the views of people with disabilities about PMR, including return of biological, environmental, and lifestyle results. Given the national investment in recruiting diverse and underrepresented communities into PMR cohorts [13], a better understanding of the views of such a historically marginalized group as the disability community is needed.

\section{Materials and Methods}

Study methods, including the recruitment process and eligibility screening, are detailed elsewhere [27]. In brief, we conducted a disability-accessible online national survey with 1,294 adults who identified their primary condition as: (1) blindness/low vision, (2) deafness/hard-of-hearing, (3) physical disability, (4) autism, (5) intellectual/other developmental disability, (6) learning disability, or (7) mental health/psychosocial disability (Table 1 provides their demographic characteristics). After obtaining consent and screening of potential participants for eligibility criteria, the survey provided a description of PMR (see Appendix). The survey's primarily closed-ended questions were modeled on a study that explored the views of people from the general public about PMR [3]; disability-specific questions were added, including open-ended options regarding barriers to and facilitators of participation in PMR. The survey was available in English, Spanish, and American Sign Language (translated by the National Association of the Deaf). Recruitment was conducted through collaboration with national organizations of people with disabilities.

With regard to RoR, participants were asked, "If you were to participate (in PMR), what information would you like to receive?" and they were provided with a list of options: general genetic results, i.e., "my genetic results," and "ancestry based on my genetics"; health-related results, including "my medical records," 
Table 1. Demographic characteristics

\begin{tabular}{|c|c|c|}
\hline Demographic variable & $N$ & $\%$ \\
\hline \multicolumn{3}{|l|}{ Primary disability/condition $(n=1,294)$} \\
\hline Blindness or low vision & 271 & 21 \\
\hline Deafness or hard of hearing & 267 & 21 \\
\hline Physical disability & 273 & 21 \\
\hline Autism & 104 & 8 \\
\hline Intellectual or developmental disability & 128 & 10 \\
\hline Learning disability & 136 & 11 \\
\hline Mental health or psychosocial disability & 115 & 9 \\
\hline Multiple disabilities/conditions $(n=1,294)$ & 323 & 25 \\
\hline \multicolumn{3}{|l|}{ Age (years; $n=1,294)$} \\
\hline $18-29$ & 646 & 50 \\
\hline $30-59$ & 551 & 43 \\
\hline 60 or older & 97 & 7 \\
\hline \multicolumn{3}{|l|}{ Gender $(n=1,190)$} \\
\hline Male & 541 & 45 \\
\hline Female & 619 & 52 \\
\hline Nonbinary sex & 30 & 3 \\
\hline \multicolumn{3}{|l|}{ Race $(n=1,294)$} \\
\hline White & 850 & 66 \\
\hline Black or African American & 214 & 16 \\
\hline Other & 230 & 18 \\
\hline \multicolumn{3}{|l|}{ Ethnicity $(n=1,212)$} \\
\hline Hispanic & 448 & 37 \\
\hline Non-Hispanic & 764 & 63 \\
\hline \multicolumn{3}{|l|}{ Education level $(n=1,184)$} \\
\hline HS, GED, or less & 231 & 19 \\
\hline Some college/vocational or technical training & 566 & 48 \\
\hline BA & 196 & 17 \\
\hline Graduate & 191 & 16 \\
\hline \multicolumn{3}{|l|}{ Household income (USD; $n=1,205$ ) } \\
\hline Less than 20,000 & 230 & 19 \\
\hline $20,000-55,999$ & 594 & 49 \\
\hline More than 56,000 & 381 & 32 \\
\hline \multicolumn{3}{|l|}{ Residence $(n=1,224)$} \\
\hline Urban (city) & 573 & 47 \\
\hline Suburb (neighborhood outside the city) & 545 & 44 \\
\hline Rural (in the country) & 106 & 9 \\
\hline \multicolumn{3}{|l|}{ Employment status (check all that apply) $\left(n=1,278^{\mathrm{a}}\right)$} \\
\hline Full-time employment & 497 & 39 \\
\hline Part-time employment & 339 & 27 \\
\hline Stay at home parent & 65 & 5 \\
\hline Full-time/part time student & 192 & 15 \\
\hline Unable to work & 25 & 2 \\
\hline Other (not employed, retired, volunteer) & 244 & 19 \\
\hline
\end{tabular}

The sample size varies due to missing values. ${ }^{a}$ Respondents who provided 2 employment statuses (e.g., full time employed and student) are included in both categories. Sixteen respondents were excluded due to conflicting answers (e.g., both employed full time/ part time and not employed. "health information based on my family history," "lab results (cholesterol, blood sugar, etc.)"; and lifestyle results (i.e., "nutritional information, dietary analysis"). The list also included options to receive environmental results ("information about water or air quality around my home"), comparative results ("how my health and lifestyle compare to other participants"), and research opportunities ("information about other research studies related to health"). In addition, participants were asked about specific genetic risks, i.e., "would you want to know if researchers found out that you have a genetic risk for: (1) 'a treatable disease like asthma'; (2) 'untreatable disease like Alzheimer's'; and (3) 'a bad reaction to certain types of medicine'." Participants were requested to "select all that apply" with regards to the list of possible results.

Data analysis was conducted with SPSS (IBM) 24.0 and SAS 9.4 software, using counts and percentages for overall responses and demographic characteristics, $\chi^{2}$ tests for comparing differences among groups of categorical variables, and the usual procedures of collapsing and recoding covariates when data cells were small to reduce the number of categories for analysis. $p<0.05$ was considered statistically significant. Participants' responses to the openended questions were incorporated into the discussion as relevant.

\section{Results}

\section{Overall Interest in Results from PMR}

The results for all of the participants are shown in Figure 1.

General Genetic Results. Most participants expressed interest in receiving "my genetic results" (78\%) and 53\% stated they would like to receive "ancestry based on my genetics."

Health-Related Results. The largest fraction of participants expressed interest in receiving "my medical record" (63\%), followed by "health information based on my family history" (61\%), and "lab results" (53\%). Almost a third (32\%) selected lifestyle results (i.e., "nutritional information, dietary analysis").

Other Information. Most participants stated that they would like to receive comparative results (62\%) and 53\% stated an interest in environmental results. A third of the participants said that they would like "information about other research studies related to health" (34\%).

Specific Genetic Results. Most participants expressed interest in receiving genetic risk results about "a treatable disease like asthma" (68\%) and "an untreatable disease like Alzheimer's" (61\%). Forty-one percent expressed interest in receiving information about "a bad reaction to certain types of medicine."

The overall interest in receiving all types of results was impacted by participants' educational attainment (all $p<$ 0.008 ). As shown in Table 2, participants with graduate degrees expressed more interest in receiving all types of infor- 


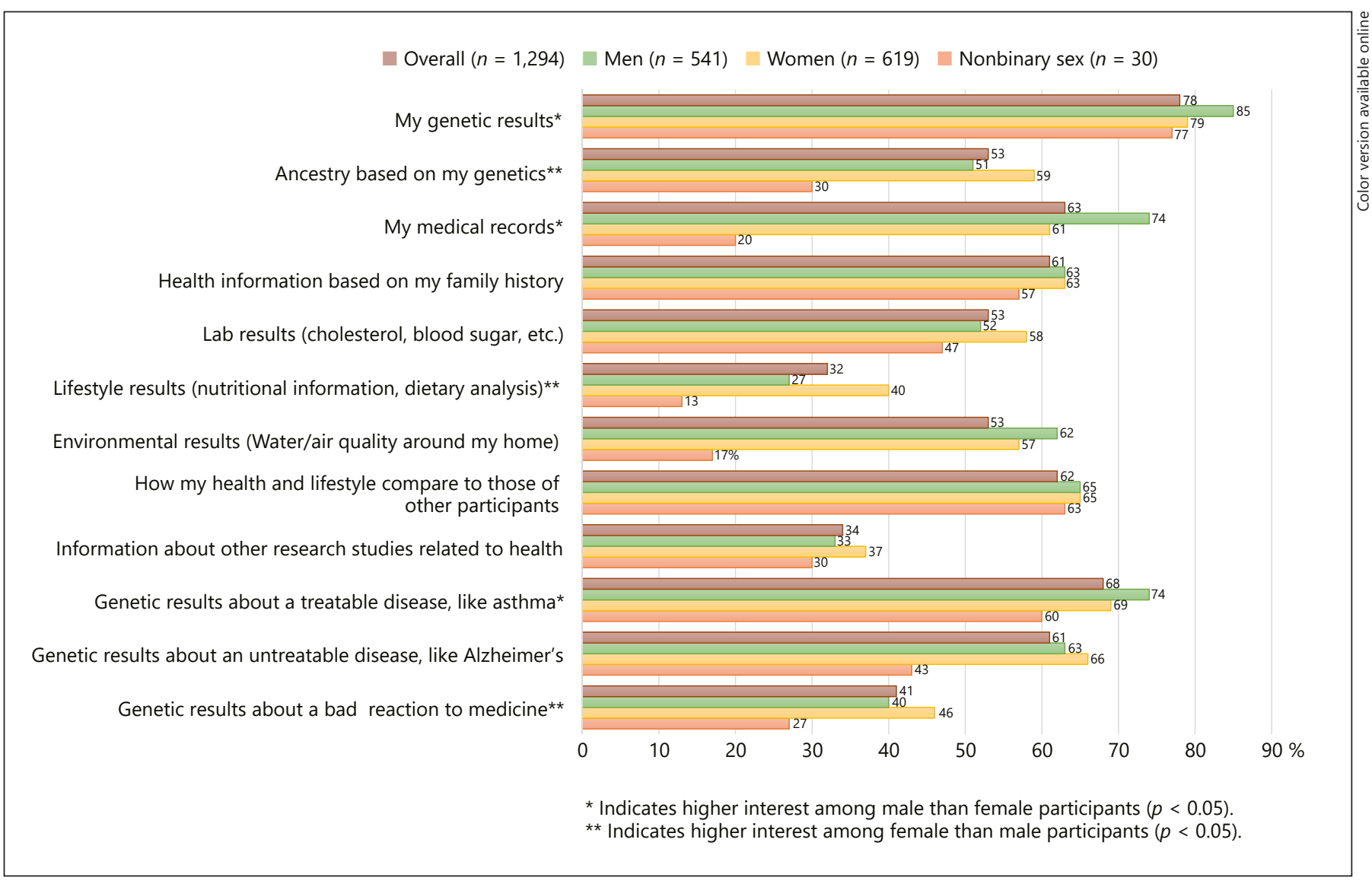

Fig. 1. Participants' views on desired RoR from PMR overall and across gender groups. Displayed results include all participants $(n=1,294)$, and gender groups (female, male, and nonbinary sex participants). ${ }^{*}$ Higher interest among male than female participants $(p<0.05)$. ${ }^{* *}$ Higher interest among female than male participants $(p<$ $0.05)$.

mation (most $p<0.001$ ), followed by those with a college education (most $p<0.047$ ), and those with a GED/high school education or less (most $p \leq 0.006$ ), while participants with vocational training or some college education were the least interested in all types of results (most $p \leq 0.033$ ). Of particular note is that participants with a GED/high school education or less expressed higher interest than other participants in receiving "my genetic results" (94 vs. $78 \%$ of other participants), medical records ( 83 vs. $61 \%$ ), environmental results ( 75 vs. $53 \%$ ), and genetic risk results about treatable disease ( $87 \mathrm{vs.} 67 \%$ ), but they were least interested in receiving lab results (38 vs. 59\%), lifestyle results (14 vs. $38 \%)$, and specific genetic risk results about a bad reaction to medication ( 34 vs. $44 \%)$ (all $p \leq 0.006)$.

\section{Differences across Gender Groups}

Results by gender groups are shown in Figure 1. Since only 30 participants identified as neither male nor female ("nonbinary sex"), our analysis focuses on differences between male and female participants. Men were more interested than women in receiving "my genetic results" (85 vs. $79 \% ; p=0.008$ ), medical record information (74 vs. $61 \% ; p<0.001$ ), and genetic results about risk for "a treatable disease like asthma" ( 74 vs. $69 \% ; p=0.046$ ). Women were more interested than men in receiving results about "ancestry based on my genetics" (59 vs. $51 \%$; $p=0.005$ ), lifestyle results ( 40 vs. $27 \%$; $p<0.001$ ), and the genetic risk for a bad reaction to medication ( 46 vs. $40 \% ; p=0.047$ ).

\section{Differences across Racial and Ethnic Groups}

As shown in Table 3, significant differences were observed across racial and ethnic groups with regard to all but one type of result, i.e., "information about other research studies related to health," which was selected by $32-36 \%$ of each racial/ethnic group. Whenever statistically significant differences were found, non-Hispanic 
Table 2. Interest in receiving types of results by educational attainment

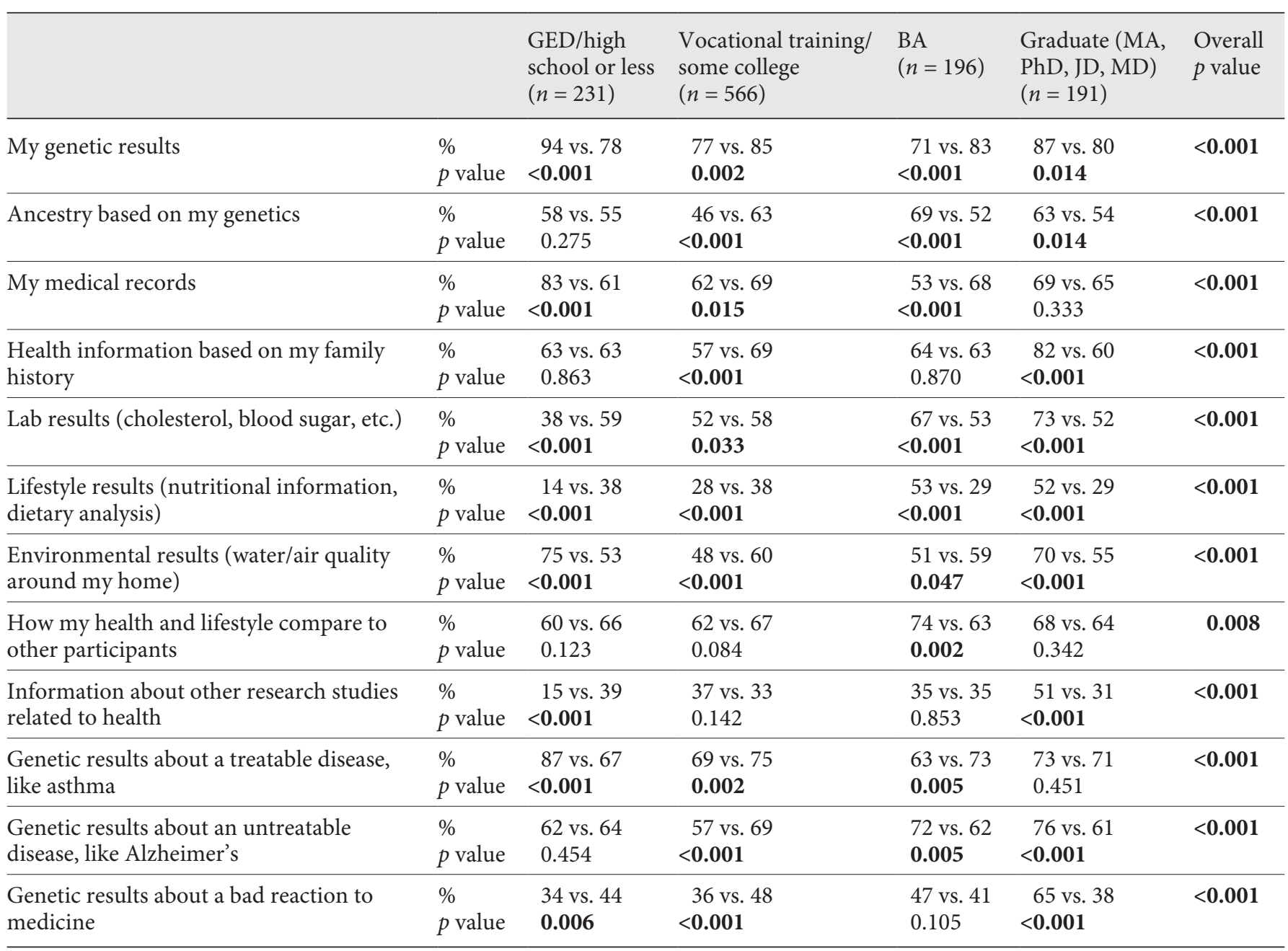

The percentage of participants within an educational attainment subgroup who responded "yes" vs. all other participants who responded "yes" is shown. Bolded findings indicate statistically significant results $(p<0.05)$.

participants were more interested than Hispanic participants, and White participants more interested than Black/ African Americans and other racial minorities (encompassing Asians, Pacific Islanders, American Indians, Native Alaskans, Native Hawaiians; "Other racial minorities") to receive most types of results (most $p<0.01$ ).

\section{Differences across Disability Subgroups}

Differences in interest in receiving results across disability subgroups were identified for all types of results (Table 4), but 3 findings are salient. First, there are observable trends in the interest of specific disability subgroups in RoR. Blind/low-vision participants were more likely to express interest in receiving most types of results, while participants who are autistic or deaf/hard of hearing or have intellectual disabilities are less likely to do so (most $p<0.01$ ).

Second, only a third or less of most disability subgroups expressed interest in receiving lifestyle results (range 16-30\%) and "information about other research studies related to health" (range 18-36\%). Two exceptions are blind/low-vision and autistic participants. For both types of results, almost half of blind/low-vision (respectively, 44 and $48 \%$ ) and most autistic participants (respectively, 60 and 62\%) expressed interest in receiving such information.

Finally, there are significant differences in types of results that are key to PMR, specifically: "my genetic 
Table 3. Overall interest and differences across racial and ethnic groups in receiving results from PMR

\begin{tabular}{|c|c|c|c|c|c|c|c|c|c|}
\hline & $\begin{array}{l}\text { Overall, } \\
\%\end{array}$ & $\begin{array}{l}\text { Whites, } \\
\%\end{array}$ & $\begin{array}{l}\text { Blacks/ } \\
\text { African } \\
\text { Americans, \% }\end{array}$ & $p$ value $^{\mathrm{a}}$ & $\begin{array}{l}\text { Other } \\
\text { racial } \\
\text { minorities, \% }\end{array}$ & $p$ value $^{\mathrm{b}}$ & $\begin{array}{l}\text { Hispanics, } \\
\%\end{array}$ & $\begin{array}{l}\text { Non- } \\
\text { Hispanics, } \\
\%\end{array}$ & $p$ value \\
\hline My genetic results & 78 & 87 & 61 & $<0.0001$ & 60 & $\begin{array}{r}<\mathbf{0 . 0 0 0 1} \\
0.7935\end{array}$ & 72 & 87 & $<0.001$ \\
\hline Ancestry based on my genetics & 53 & 56 & 53 & 0.4353 & 40 & $\begin{array}{l}<0.0001 \\
<0.0038\end{array}$ & 43 & 62 & $<0.001$ \\
\hline My medical records & 63 & 76 & 41 & $<0.0001$ & 34 & $\begin{array}{l}<0.0001 \\
0.17\end{array}$ & 50 & 74 & $<0.001$ \\
\hline $\begin{array}{l}\text { Health information based on my family } \\
\text { history }\end{array}$ & 61 & 64 & 52 & 0.0012 & 54 & $\begin{array}{l}\mathbf{0 . 0 0 5 5} \\
0.6712\end{array}$ & 49 & 72 & $<0.001$ \\
\hline Lab results (cholesterol, blood sugar, etc.) & 53 & 55 & 51 & 0.2398 & 46 & $\begin{array}{l}\mathbf{0 . 0 1 1 9} \\
0.3071\end{array}$ & 52 & 58 & 0.042 \\
\hline $\begin{array}{l}\text { Lifestyle results (nutritional information, } \\
\text { dietary analysis) }\end{array}$ & 32 & 35 & 28 & 0.06 & 26 & $\begin{array}{l}\mathbf{0 . 0 0 8 6} \\
0.5707\end{array}$ & 26 & 38 & $<0.001$ \\
\hline $\begin{array}{l}\text { Environmental results (water/air quality } \\
\text { around my home) }\end{array}$ & 53 & 65 & 39 & $<0.0001$ & 36 & $\begin{array}{r}<0.0001 \\
0.5571\end{array}$ & 30 & 74 & $<0.001$ \\
\hline $\begin{array}{l}\text { How my health and lifestyle compare } \\
\text { to other participants }\end{array}$ & 62 & 64 & 66 & 0.6287 & 49 & $\begin{array}{l}0.0003 \\
0.0014\end{array}$ & 58 & 69 & $<0.001$ \\
\hline $\begin{array}{l}\text { Information about other research studies } \\
\text { related to health }\end{array}$ & 34 & 35 & 38 & 0.0353 & 34 & $\begin{array}{l}0.7214 \\
0.1482\end{array}$ & 36 & 34 & 0.434 \\
\hline $\begin{array}{l}\text { Genetic results about a treatable disease, } \\
\text { like asthma }\end{array}$ & 68 & 77 & 51 & $<0.0001$ & 48 & $\begin{array}{r}<0.0001 \\
0.5688\end{array}$ & 56 & 80 & $<0.001$ \\
\hline $\begin{array}{l}\text { Genetic results about an untreatable } \\
\text { disease, like Alzheimer's }\end{array}$ & 61 & 65 & 63 & 0.4637 & 46 & $\begin{array}{r}<0.0001 \\
0.0003\end{array}$ & 52 & 72 & $<0.001$ \\
\hline $\begin{array}{l}\text { Genetic results about a bad reaction to } \\
\text { medicine }\end{array}$ & 41 & 45 & 31 & $<0.0001$ & 36 & $\begin{array}{l}\mathbf{0 . 0 1 1 4} \\
0.2421\end{array}$ & 28 & 52 & $<0.001$ \\
\hline
\end{tabular}

${ }^{a}$ Whites vs. Blacks/African Americans. ${ }^{b}$ First line: Whites vs. Other racial minorities; second line: Blacks/African Americans vs. Other racial minorities. Bolded findings indicate statistically significant results $(p<0.05)$.

results," lifestyle, and environmental results. Participants who are blind/low vision ( 84 vs. $76 \%$ among participants with other disabilities; $p=0.007$ ) and those with physical ( $85 \mathrm{vs.} 76 \%$; $p=0.003$ ) or intellectual ( 85 vs. $77 \% ; p=0.041$ ) disabilities were more interested in receiving "my genetic results," while participants who are deaf/hard of hearing ( 69 vs. $81 \% ; p<0.001$ ) or autistic (50 vs. $81 \%$; $p<0.001$ ) were less interested. Participants who are blind/low vision (44 vs. $29 \%$; $p<$ 0.001 ) or autistic ( 60 vs. $30 \% ; p<0.001$ ) had more interest in lifestyle results, whereas those with intellectual (18 vs. $34 \% ; p<0.001$ ) or learning disabilities (16 vs. $34 \% ; p<0.001)$ had less interest in this information. Participants with physical ( 65 vs. $53 \%, p<0.001$ ), learning ( 64 vs. $54 \%, p=0.031$ ) or psychosocial ( $67 \%$ vs. $54 \%$; $p=0.008)$ disabilities were more interested in receiving environmental results, while those who are deaf/hard of hearing ( 46 vs. $58 \%$; $p=0.001$ ) or autistic (41 vs. $57 \%$; $p=0.003)$ had less interest.

\section{Discussion}

As PMR initiatives move forward and collect biological, environmental, and lifestyle-related data, the scope of results that may be returned to research participants is likely to extend beyond the traditional focus on clinical genomic findings. Indeed, access to research findings is increasingly viewed as an extension of informed consent and personal choice in research participation, including PMR [2], with some scholars also suggesting that it is - or should be recognized as - a participant's right [28]. RoR 
Table 4. Comparisons of each disability subgroup with all other subgroups regarding results desired to be returned

\begin{tabular}{|c|c|c|c|c|c|c|c|}
\hline & $\begin{array}{l}\text { Blind/low- } \\
\text { vision, \% }\end{array}$ & $\begin{array}{l}\text { Deaf/hard of } \\
\text { hearing, } \%\end{array}$ & $\begin{array}{l}\text { Physical, } \\
\%\end{array}$ & $\begin{array}{l}\text { Autism, } \\
\%\end{array}$ & $\begin{array}{l}\text { Intellectual, } \\
\%\end{array}$ & $\begin{array}{l}\text { Learning, } \\
\%\end{array}$ & $\begin{array}{l}\text { Psychosocial, } \\
\%\end{array}$ \\
\hline My genetic results & $\begin{array}{l}84 \text { vs. } 76 \\
p=\mathbf{0 . 0 0 7}\end{array}$ & $\begin{array}{l}69 \text { vs. } 81 \\
p<0.001\end{array}$ & $\begin{array}{l}85 \text { vs. } 76 \\
p=0.003\end{array}$ & $\begin{array}{l}50 \text { vs. } 81 \\
\boldsymbol{p}<\mathbf{0 . 0 0 1}\end{array}$ & $\begin{array}{l}85 \text { vs. } 77 \\
p=\mathbf{0 . 0 4 1}\end{array}$ & $\begin{array}{l}82 \text { vs. } 78 \\
p=0.288\end{array}$ & $\begin{array}{l}84 \text { vs. } 78 \\
p=0.141\end{array}$ \\
\hline Ancestry based on my genetics & $\begin{array}{l}58 \text { vs. } 51 \\
p=\mathbf{0 . 0 4 1}\end{array}$ & $\begin{array}{l}54 \text { vs. } 53 \\
p=0.673\end{array}$ & $\begin{array}{l}55 \text { vs. } 52 \\
p=0.420\end{array}$ & $\begin{array}{l}58 \text { vs. } 52 \\
p=0.296\end{array}$ & $\begin{array}{l}45 \text { vs. } 54 \\
p=0.049\end{array}$ & $\begin{array}{l}43 \text { vs. } 54 \\
p=0.020\end{array}$ & $\begin{array}{l}48 \text { vs. } 53 \\
p=0.265\end{array}$ \\
\hline My medical records & $\begin{array}{l}67 \text { vs. } 62 \\
p=0.086\end{array}$ & $\begin{array}{l}51 \text { vs. } 66 \\
p<\mathbf{0 . 0 0 1}\end{array}$ & $\begin{array}{l}66 \text { vs } 62 \\
p=0.163\end{array}$ & $\begin{array}{l}78 \text { vs. } 61 \\
p=0.001\end{array}$ & $\begin{array}{l}49 \text { vs. } 64 \\
p=0.001\end{array}$ & $\begin{array}{l}64 \text { vs. } 63 \\
p=0.741\end{array}$ & $\begin{array}{l}70 \text { vs. } 62 \\
p=0.071\end{array}$ \\
\hline $\begin{array}{l}\text { Health information based on my family } \\
\text { history }\end{array}$ & $\begin{array}{l}62 \text { vs. } 60 \\
p=0.594\end{array}$ & $\begin{array}{l}57 \text { vs. } 61 \\
p=0.218\end{array}$ & $\begin{array}{l}65 \text { vs. } 60 \\
p=0.106\end{array}$ & $\begin{array}{l}44 \text { vs. } 62 \\
p<0.001\end{array}$ & $\begin{array}{l}70 \text { vs. } 60 \\
p=0.029\end{array}$ & $\begin{array}{l}61 \text { vs. } 61 \\
p=0.911\end{array}$ & $\begin{array}{l}59 \text { vs. } 61 \\
p=0.738\end{array}$ \\
\hline Lab results (cholesterol, blood sugar, etc.) & $\begin{array}{l}71 \text { vs. } 48 \\
p<0.001\end{array}$ & $\begin{array}{l}49 \text { vs. } 54 \\
p=0.112\end{array}$ & $\begin{array}{l}54 \text { vs. } 53 \\
p=0.862\end{array}$ & $\begin{array}{l}33 \text { vs. } 55 \\
p<0.001\end{array}$ & $\begin{array}{l}51 \text { vs. } 53 \\
p=0.594\end{array}$ & $\begin{array}{l}46 \text { vs. } 54 \\
p=0.98\end{array}$ & $\begin{array}{l}49 \text { vs. } 53 \\
p=0.331\end{array}$ \\
\hline $\begin{array}{l}\text { Lifestyle results (nutritional information, } \\
\text { dietary analysis) }\end{array}$ & $\begin{array}{l}44 \text { vs. } 29 \\
p<0.001\end{array}$ & $\begin{array}{l}30 \text { vs. } 33 \\
p=0.496\end{array}$ & $\begin{array}{l}28 \text { vs } 33 \\
p=0.092\end{array}$ & $\begin{array}{l}60 \text { vs } 30 \\
p<0.001\end{array}$ & $\begin{array}{l}18 \text { vs. } 34 \\
p<0.001\end{array}$ & $\begin{array}{l}16 \text { vs. } 34 \\
p<0.001\end{array}$ & $\begin{array}{l}27 \text { vs } 33 \\
p=0.218\end{array}$ \\
\hline $\begin{array}{l}\text { Environmental results (water/air quality } \\
\text { around my home) }\end{array}$ & $\begin{array}{l}52 \text { vs. } 56 \\
p=0.181\end{array}$ & $\begin{array}{l}46 \text { vs. } 58 \\
p=0.001\end{array}$ & $\begin{array}{l}65 \text { vs. } 53 \\
p<0.001\end{array}$ & $\begin{array}{l}41 \text { vs. } 57 \\
p=0.003\end{array}$ & $\begin{array}{l}52 \text { vs. } 56 \\
p=0.485\end{array}$ & $\begin{array}{l}64 \text { vs. } 54 \\
p=0.031\end{array}$ & $\begin{array}{l}67 \text { vs. } 54 \\
p=0.008\end{array}$ \\
\hline $\begin{array}{l}\text { How my health and lifestyle compare to } \\
\text { other participants }\end{array}$ & $\begin{array}{l}53 \text { vs. } 65 \\
p<0.001\end{array}$ & $\begin{array}{l}64 \text { vs. } 62 \\
p=0.452\end{array}$ & $\begin{array}{l}74 \text { vs. } 59 \\
p<\mathbf{0 . 0 0 1}\end{array}$ & $\begin{array}{l}44 \text { vs. } 64 \\
p<0.001\end{array}$ & $\begin{array}{l}64 \text { vs. } 62 \\
p=0.622\end{array}$ & $\begin{array}{l}69 \text { vs. } 61 \\
p=0.071\end{array}$ & $\begin{array}{l}57 \text { vs. } 63 \\
p=0.280\end{array}$ \\
\hline $\begin{array}{l}\text { Information about other research studies } \\
\text { related to health }\end{array}$ & $\begin{array}{l}48 \text { vs. } 30 \\
p<0.001\end{array}$ & $\begin{array}{l}26 \text { vs. } 36 \\
p=0.002\end{array}$ & $\begin{array}{l}26 \text { vs. } 36 \\
p=0.002\end{array}$ & $\begin{array}{l}62 \text { vs. } 31 \\
p<0.001\end{array}$ & $\begin{array}{l}30 \text { vs. } 34 \\
p=0.312\end{array}$ & $\begin{array}{l}18 \text { vs. } 36 \\
p<0.001\end{array}$ & $\begin{array}{l}35 \text { vs. } 34 \\
p=0.796\end{array}$ \\
\hline $\begin{array}{l}\text { Genetic results about a treatable disease, } \\
\text { like asthma }\end{array}$ & $\begin{array}{l}68 \text { vs. } 68 \\
p=0.990\end{array}$ & $\begin{array}{l}57 \text { vs. } 71 \\
p<0.001\end{array}$ & $\begin{array}{l}73 \text { vs. } 68 \\
p=0.067\end{array}$ & $\begin{array}{l}73 \text { vs. } 68 \\
p=0.241\end{array}$ & $\begin{array}{l}67 \text { vs. } 68 \\
p=0.850\end{array}$ & $\begin{array}{l}79 \text { vs } 67 \\
p=0.005\end{array}$ & $\begin{array}{l}66 \text { vs. } 68 \\
p=0.658\end{array}$ \\
\hline $\begin{array}{l}\text { Genetic results about an untreatable disease, } \\
\text { like Alzheimer's }\end{array}$ & $\begin{array}{l}59 \text { vs. } 62 \\
p=0.378\end{array}$ & $\begin{array}{l}64 \text { vs. } 61 \\
p=0.249\end{array}$ & $\begin{array}{l}72 \text { vs. } 59 \\
p<\mathbf{0 . 0 0 1}\end{array}$ & $\begin{array}{l}42 \text { vs. } 63 \\
p<0.001\end{array}$ & $\begin{array}{l}52 \text { vs. } 62 \\
p=\mathbf{0 . 0 1 6}\end{array}$ & $\begin{array}{l}60 \text { vs. } 62 \\
p=0.648\end{array}$ & $\begin{array}{l}64 \text { vs. } 61 \\
p=0.491\end{array}$ \\
\hline $\begin{array}{l}\text { Genetic results about a bad reaction to } \\
\text { medicine }\end{array}$ & $\begin{array}{l}65 \text { vs. } 35 \\
p<\mathbf{0 . 0 0 1}\end{array}$ & $\begin{array}{l}29 \text { vs. } 45 \\
\boldsymbol{p}<\mathbf{0 . 0 0 1}\end{array}$ & $\begin{array}{l}43 \text { vs. } 41 \\
p=0.665\end{array}$ & $\begin{array}{l}27 \text { vs. } 43 \\
p=\mathbf{0 . 0 0 2}\end{array}$ & $\begin{array}{l}31 \text { vs. } 43 \\
p=\mathbf{0 . 0 1 5}\end{array}$ & $\begin{array}{l}35 \text { vs. } 42 \\
p=0.130\end{array}$ & $\begin{array}{l}44 \text { vs. } 41 \\
p=0.626\end{array}$ \\
\hline
\end{tabular}

The percentage of participants within a disability subgroup vs. participants with other disabilities is shown. Light gray represents findings of "more likely." Dark gray represents findings of "less likely." Bolded findings indicate statistically significant results $(p<0.05)$.

is further driven by emerging notions of participation, reciprocity, and social justice in health research. In a shift away from previous practices that viewed research subjects as mere providers of data, research participants today are viewed as partners and agents of change, i.e., "individuals (who) want and deserve to know (their) results" to change their health trajectories [12]. Since diversity in PMR cohorts is essential for racially/ethnically relevant findings to emerge, RoR has also been suggested as an incentive for research participation [4], increasing the odds that underrepresented minorities will enroll into PMR in exchange for data that may not otherwise be available to them. As scholars have suggested, while RoR builds on "pop cultural curiosity of genetics" and a high interest in learning personal disease risk information $[29,30]$, this practice may serve as a trust-building measure [17], a step toward reversing the underrepresentation of racial and ethnic minorities in genomic research [31-36]. However, these goals and the potential for PMR to translate into therapeutic and preventive care measures are only likely to be achieved if all potential research participants share this interest.

Our study explored questions about RoR from PMR with a large sample of people with disabilities, the largest health disparities group in the USA. The greatest interest was found regarding biological results: a majority of the participants expressed interest in receiving genetic results, medical records, health information based on family history, specific genetic results about an increased risk for treatable and untreatable diseases, and data about how their health and lifestyle compare with other participants'. About half of the participants stated that they would be interested in receiving nongenomic laboratory results, genetic ancestry findings, environmental results, 
and data on genetic risk for adverse reactions to medication. Only a third expressed interest in receiving lifestyle information and other health research opportunities.

The general interest in receiving biological, health-related information is consistent with existing studies [3, $10,37]$, and comments by several participants indicate that receiving results may incentivize participation in PMR. As one participant commented, a factor that would increase the likelihood of participation in PMR is "getting some of the information from the study in ways that I could take advantage of," and another highlighted "having access to data and outcomes throughout the process. People are forever wanting to 'study' people who are different, with few wanting to share the results of such study with the subjects." However, our findings that the interest in receiving such results varied by participants' educational level suggest that the use of RoR as an incentive may not be sufficient for enrolling diverse populations. As the expressed interest in receiving biological, healthrelated information among participants with a GED/high school education or less was mixed, and it was lowest among participants with vocational training or some college education (contrary to others' findings that interest in results increases with participants' educational attainment [17]), further research is needed to better understand participants' rationales for these choices.

Overall, a large majority of our sample expressed interest in receiving their genetic results - indeed, higher than found in the 2016 study of the general public (78 vs. $74 \%$ [3]). This interest was particularly high among participants with graduate degrees $(87 \%)$ and in contrast to an earlier study [17] also among those with GED/high school education or less $(94 \%)$. However, this high interest was stratified across various subgroups of people with disabilities. Whereas a large majority of the participants who are blind/low vision, or with physical, intellectual, learning, and psychosocial disabilities, expressed interest in receiving genetic results (82-85\%), 69\% of deaf/hard-of-hearing participants and only $50 \%$ of autistic participants expressed such interest. Because genetic results from PMR can encompass a range of findings, it is possible that participants' responses reflected different interpretations of what these results would entail. For some participants, "my genetic results" may have been associated with results about the genetics of common diseases such as cancer, which may be less available or accessible to them in general medical practice [38] and thus more valuable in the context of PMR. For others, it may have meant primarily genetics of their specific conditions (e.g., blindness and autism), which they may find more or less useful de- pending on other factors relating to their experiences as people with disabilities.

The latter possibility is consistent with our earlier reports that blind/low-vision participants expressed more willingness [39], whereas deaf/hard-of-hearing and autistic participants expressed less willingness to provide various types of data for PMR, e.g., family history and genetics [40]. It is also consistent with other studies showing variance in views about genetic testing among subgroups of people with disabilities. Studies of patients with inherited vision conditions found support in genetic testing for the purpose of identifying novel treatments for blindness [21], and a study of blind people found general support in scientific progress aimed at sight restoration, including gene therapy, but also that factors such as when the blindness was acquired may impact these views [41]. Studies of deaf individuals found growing interest in genetic testing and counseling for deafness, but also that this interest may be impacted by issues such as affiliation with the Deaf community and concerns that genetic data will be used against this community [42]. Conversely, a study of people who identify as Autistic and have awareness of the neurodiversity movement found high endorsement of biological attributions for autism but rejection of the medical (including genetic) focus on the causes of autism [43]. While our survey did not explore questions of affiliation with these disability communities, it is possible that especially deaf/hard-of-hearing and autistic participants in our study - all of whom were recruited through national organizations of people with disabilities - shared these views.

However, the interest expressed by our participants in receiving many other types of results was lower than found in other studies (2 exceptions are genetic results [discussed above] and comparative health/lifestyle results [see below]). In particular, smaller proportions of participants in our study who expressed interest, compared to the reported interest found in a sample of the general public [3], in receiving results that comprise the key components of PMR: biological and medical results, i.e., medical record information ( $63 \%$ among our participants vs. $68 \%$ of participants from the general public), nongenomic laboratory results (53 vs. $75 \%$ ), health information based on family history (61 vs. 67\%), environmental findings (53 vs. $66 \%$ ), and lifestyle findings ( 32 vs. $65 \%$ ). The interest of our participants in receiving specific results was also lower than found in other studies about genetic research (though different wording and study designs complicate direct comparison). For instance, smaller fractions of our participants were interested in receiving results of in- 
creased risk for treatable diseases ( 68 vs. $77 \%$ in a study of women diagnosed with cancer [37] and $90 \%$ in a study of participants in a biobank [10]) and in receiving results of increased risk for adverse reactions to medication (41 vs. $74 \%$ in the study of women with cancer [37]).

Several explanations may account for this lower interest. First, these findings may reflect a disconnect from the medical establishment, which has long been criticized by people with disabilities for its focus on the medical aspects of disability, often in disregard of the sociocultural barriers to inclusion in society. As one participant expressed, "This might not be too relevant to this kind of study, but I do have some philosophical concerns about the concept of 'healing' people with disabilities, because such efforts view disability through a medical model ...." Similarly, another participant expressed greater willingness to participate in PMR, "If the researchers had an understanding of the social model of disability and understood that many disabled people with non-painful disabilities aren't interested in a cure."

Concerns about lack of measures to ensure accessibility to the results may have also impacted participants' responses. As reflected in numerous comments added by participants in our study, it is critical for study data to be provided in disability-accessible formats. These include "plain, simple language," "electronic, Braille or audio recording" and ensuring that "ASL format is always produced and provided for those deaf people who prefer to receive info in their native language." More generally, as one participant added regarding barriers to participation: "It may be difficult to get access to the information required, or to save records required because equipment is inaccessible." Because disability-accessible data are often limited or unavailable in many healthcare and research settings [44, 45], participants' relatively low interest in receiving results may reflect previous negative experiences with inaccessible healthcare systems.

Similar rationales may explain why our participants expressed far less interest than the general public in receiving "information about other research studies related to health" (34 vs. $60 \%$ [3]). People with disabilities are often excluded from clinical trials and other mainstream health research for reasons that include using comorbidities, including disability [45], as exclusion criteria [46], inaccessible study materials [44], and concerns about obtaining consent, e.g., from people with intellectual disabilities [47]. As one participant stated, "they (i.e., PM researchers) will not want to include people with disabilities," even as the survey's description of a proposed PMR study stated that the cohort will "include men and women of all ages from many places and backgrounds in the United States." Rather than struggle to participate in what often turns out to be noninclusive environments, especially when a study may seem to have no direct or immediate impact on daily life, participants in our study may have preferred not even to learn about other research opportunities.

Moreover, our finding of high interest in RoR, though lower than the general public's, is only partial and requires qualification; this finding may apply only to participants who are not from minority groups. Indeed, for almost all types of results (including most genetic and environmental results), and whenever significant differences were identified, participants who identified as Hispanic, Black/African Americans, Other racial minorities or nonbinary sex were less interested in receiving results compared to non-Hispanic, White, and binary sex participants. Lower interest was particularly evident among participants from Other racial minorities: less than half of these participants expressed interest in receiving most types of results and only a third or fewer expressed interest in receiving their medical record, findings about an increased genetic risk for adverse reactions to medication, environmental results, lifestyle results, and other health research opportunities.

Scholars studying the impact of race and ethnicity on views about return of genetic results have suggested that lower interest among minority groups may reflect concerns about a lack of access to healthcare that would allow them to follow up on actionable results [15] and distrust in the clinical and/or research community $[10,48]$. Similar concerns may exist among our participants from racial and ethnic minorities, though they may be further compounded by participants' "othering" within their communities. That is, in addition to concerns shared with other minority group members, they may experience additional disability-specific sources of distrust, e.g., history of abuse in research, prevalent stereotypes of a genetic inferiority of people with disabilities both within and outside their racial/ethnic communities, and experiences of stigma and discrimination in healthcare and society [49]. As one participant commented, "Parts (of PMR) may be useful but it sounds [too] creepily eugenics supporting. If the researchers had extensive knowledge and experience in disability social justice history and issues, and WERE disabled themselves, it would be better."

Issues of social justice and tensions between inclusion and exclusion may also explain our findings about the higher interest of our participants in receiving some results. Participants expressed higher interest than found among the general public in receiving results about how 
their health and lifestyle compare to other participants (62 vs. 57\% [3]) and blind/low-vision and autistic participants expressed a far higher interest in learning about other health research opportunities compared to participants with other types of disabilities (respectively, 48 vs. $30 \%$ and 62 vs. $31 \%$ ). Although these may seem 2 disparate findings, both can be explained by participants' struggle for equality and inclusion. Comparisons of health and lifestyle outcomes among research participants can provide a benchmark for inequality, allowing disenfranchised groups to call attention to their needs. Likewise, learning about other research opportunities may inform advocacy strategies of subgroups of people with disabilities that are invested in health research. Members of the Autistic/Neuro-diverse community, e.g., have criticized the high proportion of funding for research on the biology and risk factors of autism (respectively, 35 and 24\%) compared to research on services and lifespan issues relevant for autistic people (respectively, 5 and 2\%) [50]. Being informed about other studies may allow these communities to engage with, and potentially impact, the direction of future research.

\section{Future Directions}

Taken together, our findings indicate that there is no one voice within the disability community regarding the return of genetic results from PMR. Rather, views on this issue are likely impacted by a variety of factors from gender, race/ethnicity, and levels of educational attainment to type of disability and sociocultural constructs of health and illness (some of which were not explored in this study). Our findings are nonetheless relevant to the PMR enterprise. Without active "genomic citizens" who are invested in learning about and acting on their genomic and health-related results, the likelihood of achieving the therapeutic and preventive goals of precision medicine is reduced. Future research should explore the reasons underlying these differences, having in mind 2 key issues.

First, although gender, race, and ethnicity are used as key markers of diversity, disability-based minority status may play an equal or greater role in decisions about RoR from PMR. As our sample did not allow for further analysis of race/ethnicity/gender within subgroups of people with disabilities, further research will be necessary to better understand the impact of both disability-related factors and interactions among experiences of minority statuses on views about RoR.

Second, research on racial/ethnic minorities has identified a "spillover effect," whereby decisions to participate in PMR are inextricable from personal and group experiences of racism and discrimination in biomedical research and clinical care [51]. Participants' comments in our study may suggest that the spillover may encompass, on the one hand, negative experiences of ableism in research and medicine (e.g., inaccessibility, history of eugenics) and, on the other hand, decisions about return of genetic and other results from PMR. Further research can explore these issues in the future. In the meantime, insofar as the RoR is viewed as an incentive for research participation [4], it may only be a very partial strategy.

It will be important for researchers to understand these contextual factors and to develop measures to address these concerns. Educating precision medicine researchers about social justice and disability history and needs is a first step for increasing awareness of these issues [52]. Providing disability-accessible information about PMR and its goals is needed as well to ensure equality of opportunities to benefit from such research. Working with disability communities to identify the sources of concerns is critical for developing trust in PMR, as is implementing measures to reverse the negative impact of intersectionalities - disability, gender and race/ethnicity - on research participation and views relating to RoR. Without better understanding of views and concerns of underrepresented populations, the hope for PMR to improve the health of individuals (and groups) by returning results will face a steep challenge to fulfilling its goal.

\section{Acknowledgement}

We gratefully acknowledge the support of the Association of University Centers on Disabilities (AUCD), the National Council on Independent Living (NCIL), the National Federation of the Blind (NFB), the National Association of the Deaf (NAD), and the American Association of Health and Disability (AAHD), which assisted with recruitment, survey material, and programming. We also gratefully acknowledge the support of individuals who assisted in this process: Lou Ann Blake, Howard A. Rosenblum, Lizzie Sorkin, Abiodun Ramroop, Dawn Rudolph, Kelly Buckland, Cara Liebowitz, Mark Starford, Marcia Orland, Kecia Brooke Weller, Charlene Jones, Roberta Carlin, Carlos Ríos Espinosa, Anthony Stephens (American Council of the Blind), Kathy Guernsey, Amar D. Mandavia, and Dave Kaufman. Finally, we thank the numerous individuals who took the time to participate in our study.

\section{Statement of Ethics}

The IRB at the NY State Psychiatric Institute approved this study and electronic informed consent from all participants involved in the study was obtained. 


\section{Disclosure Statement}

Maya Sabatello is a member of the All of Us Research Program's Institutional Review Board. The authors declare no other conflict of interests.

\section{Funding Sources}

This work was supported by NHGRI grants K01HG008653 and RM1HG007257, NHGRI/All of Us Research Program grant 3P50HG007257-05S1, and NIH Office of The Director (OD).

\section{Author Contributions}

Maya Sabatello conceived the notion of this project; led the study design, acquisition, analysis, interpretation of data, and funding for this project; prepared the initial draft and revised this paper for submission. Yuan Zhang contributed to data analysis and interpretation. Ying Chen contributed to data analysis and interpretation and development of tables. Paul S. Appelbaum codesigned this study and contributed to the study material, funding for the project, and critical review of this paper. All of the authors gave final approval of the version of this paper to be published.

\section{Appendix A}

Text Used to Describe a National PMR Cohort Study in the Survey

Many diseases are caused by a mix of genetics (what you inherit from your family), the environment, and lifestyle. To figure out how they cause diseases, a large number of people need to be studied for a long time.
The National Institutes of Health plans a study of 1 million volunteers for 10 years or longer. It is aimed at helping doctors choose medicines and other treatments based on a person's genetics, environment, and lifestyle. This is called "precision medicine research."

We want to know what you think about PMR and what problems you might face if you volunteered to be a participant in the research.

The National Institutes of Health study will collect personal information and samples (like blood and saliva) from 1 million volunteers. It includes men and women of all ages from many places and backgrounds in the USA.

Researchers will follow participants' health over many years. Participants will agree to give researchers access to their medical records and information about their lifestyle. They will also give blood and other samples for genetic and lab tests, like cholesterol and blood sugar.

Researchers will explain the risks and benefits of being in the study. All volunteers will decide for themselves if they would like to participate.

Participants might be asked to:

- Complete research surveys

- Keep a food diary

- Track daily exercise or heart rate with a Fitbit or smartphone - Provide samples, like water or soil, from around their homes.

All samples and lab test results will be "coded." Coding means the names and personal information of each participant will be replaced with a number. All coded information will be stored in a secure computer.

Researchers will use the coded information to study how genetics, environment, and lifestyle contribute to health and disease. Participants could control how their coded information is used in research and they might get access to the information collected about their health.

\section{References}

1 Parens E, Appelbaum PS. Special report: looking for the psychosocial impacts of genomic information. Hastings Cent Rep. 2019 May; 49:S2-96.

2 Ryan KA, De Vries RG, Uhlmann WR, Roberts JS, Gornick MC. Public's Views toward Return of Secondary Results in Genomic Sequencing: It's (Almost) All about the Choice. J Genet Couns. 2017 Dec;26(6):1197-212.

3 Kaufman DJ, Baker R, Milner LC, Devaney S, Hudson KL. A survey of US adults' opinions about conduct of a nationwide Precision Medicine Initiative(R) Cohort Study of genes and environment. PLoS One. 2016 Aug; 11(8):e0160461.

4 O’Daniel J, Haga SB. Public perspectives on returning genetics and genomics research results. Public Health Genomics. 2011;14(6): 346-55.

$5 \mathrm{Yu} \mathrm{JH}$, Harrell TM, Jamal SM, Tabor HK, Bamshad MJ. Attitudes of genetics profes- sionals toward the return of incidental results from exome and whole-genome sequencing. Am J Hum Genet. 2014 Jul;95(1): 77-84.

6 Stein CM, Ponsaran R, Trapl ES, Goldenberg AJ. Experiences and perspectives on the return of secondary findings among genetic epidemiologists. Genet Med. 2019 Jul;21(7): 1541-7.

7 Klitzman R, Appelbaum PS, Fyer A, Martinez J, Buquez B, Wynn J, et al. Researchers' views on return of incidental genomic research results: qualitative and quantitative findings. Genet Med. 2013 Nov;15(11):888-95.

8 Strong KA, Zusevics KL, Bick DP, Veith R. Views of nonmedical, health system professionals regarding the return of whole genome sequencing incidental findings. WMJ. 2014 Oct;113(5):179-84

9 Wynn J, Martinez J, Duong J, Chiuzan C, Phelan JC, Fyer A, et al. Research Participants'
Preferences for Hypothetical Secondary Results from Genomic Research. J Genet Couns. 2017 Aug;26(4):841-51.

10 Allen NL, Karlson EW, Malspeis S, Lu B, Seidman CE, Lehmann LS. Biobank participants' preferences for disclosure of genetic research results: perspectives from the OurGenes, OurHealth, OurCommunity project. Mayo Clin Proc. 2014 Jun;89(6):738-46.

11 Murphy J, Scott J, Kaufman D, Geller G, LeRoy L, Hudson K. Public expectations for return of results from large-cohort genetic research. Am J Bioeth. 2008 Nov; 8(11): $36-43$.

12 The Precision Medicine Initiative Working Group. The precision medicine initiative cohort program: building a research foundation for the 21 st century medicine. 2015. Available from: https://acd.od.nih.gov/documents/reports/DRAFT-PMI-WG-Report-9-112015-508.pdf. 
13 Denny JC, Rutter JL, Goldstein DB, Philippakis A, Smoller JW, Jenkins G, et al.; All of Us Research Program Investigators. The "All of Us” Research Program. N Engl J Med. 2019 Aug;381(7):668-76.

14 d'Agincourt-Canning L, Baird P. Genetic testing for hereditary cancers: the impact of gender on interest, uptake and ethical considerations. Crit Rev Oncol Hematol. 2006 May; 58(2):114-23.

$15 \mathrm{Yu}$ JH, Crouch J, Jamal SM, Tabor HK, Bamshad MJ. Attitudes of African Americans toward return of results from exome and whole genome sequencing. Am J Med Genet A. 2013 May;161A(5):1064-72.

16 Fiallos K, Applegate C, Mathews DJ, Bollinger J, Bergner AL, James CA. Choices for return of primary and secondary genomic research results of 790 members of families with Mendelian disease. Eur J Hum Genet. 2017 May; 25(5):530-7.

17 Wilkins CH, Mapes BM, Jerome RN, VillaltaGil V, Pulley JM, Harris PA. Understanding What Information Is Valued By Research Participants, And Why. Health Aff (Millwood). 2019 Mar;38(3):399-407.

18 Krahn GL, Walker DK, Correa-De-Araujo R Persons with disabilities as an unrecognized health disparity population. Am J Public Health. 2015 Apr;105(S2 Suppl 2):S198-206.

19 Sabatello M, Schulze M, editors. Human Rights and Disability Advocacy. Philadelphia: University of Pennsylvania Press; 2014. https://doi.org/10.9783/9780812208740.

20 Nelson Schmitt SS, Leigh IW. Examining a sample of Black deaf individuals on the Deaf Acculturation Scale. J Deaf Stud Deaf Educ. 2015 Jul;20(3):283-95.

21 Bong C, Potrata B, Hewison J, McKibbin M. Attitudes of patients and relatives/carers towards genetic testing for inherited retinal disease. Eye (Lond). 2010 Oct;24(10):1622-5.

22 Blankmeyer Burke T, Snoddon K, Wilkinson E. Genetics and Deafness: a view from the inside. In: Vona B, Haaf T, editors. Genetics of Deafness. Basel: Karger; 2016. pp. 1-8.

23 Baron-Cohen S. Editorial Perspective: Neurodiversity - a revolutionary concept for autism and psychiatry. J Child Psychol Psychiatry. 2017 Jun;58(6):744-7.

24 Collins FS, Varmus H. A new initiative on precision medicine. N Engl J Med. 2015 Feb; 372(9):793-5.

25 Chen JJ, Lu TP, Chen YC, Lin WJ. Predictive biomarkers for treatment selection: statistical considerations. Biomarkers Med. 2015;9(11): 1121-35.

26 Ginsburg GS, Phillips KA. Precision Medicine: From Science To Value. Health Aff (Millwood). 2018 May;37(5):694-701.
27 Sabatello M, Chen Y, Zhang Y, Appelbaum PS. Disability inclusion in precision medicine research: a first national survey. Genet Med. 2019 Oct;21(10):2319-27.

28 Thorogood A, Dalpé G, Knoppers BM. Return of individual genomic research results: are laws and policies keeping step? Eur J Hum Genet. 2019 Apr;27(4):535-46.

29 Crawford DC, Cooke Bailey JN, Briggs FB. Mind the gap: resources required to receive, process and interpret research-returned whole genome data. Hum Genet. 2019 Jul; 138(7):691-701.

30 Sanderson SC, Linderman MD, Suckiel SA, Diaz GA, Zinberg RE, Ferryman K, et al. Motivations, concerns and preferences of personal genome sequencing research participants: baseline findings from the HealthSeq project. Eur J Hum Genet. 2016 Jan;24(1): 14-20.

31 Bentley AR, Callier S, Rotimi CN. Diversity and inclusion in genomic research: why the uneven progress? J Community Genet. 2017 Oct; $8(4): 255-66$.

32 Halbert $\mathrm{CH}$, McDonald J, Vadaparampil S, Rice L, Jefferson M. Conducting precision medicine research with African Americans. PLoS One. 2016 Jul;11(7):e0154850.

33 Considerations for meaningful collaboration with tribal populations. Available from: https://allofus.nih.gov/sites/default/files/ tribal_collab_work_group_rept.pdf.

34 Sohn H. Racial and ethnic disparities in health insurance coverage: dynamics of gaining and losing coverage over the life-course. Popul Res Policy Rev. 2017 Apr;36(2):181-201.

35 King PA. Race, justice and research. In: Kahn JP, Mastroianni AC, editors. Beyond consent: Seeking justice in Research. Oxford (NY): Oxford Univeristy Press; 1998. pp. 88-110.

36 Garrison NA. Genomic Justice for Native Americans: Impact of the Havasupai Case on Genetic Research. Sci Technol Human Values. 2013;38(2):201-23.

37 Kaphingst KA, Ivanovich J, Lyons S, Biesecker B, Dresser R, Elrick A, et al. Preferences for learning different types of genome sequencing results among young breast cancer patients: role of psychological and clinical factors. Transl Behav Med. 2018 Jan;8(1):71-9.

38 Palmer CG, Boudreault P, Berman BA, Wolfson A, Duarte L, Venne VL, et al. Bilingual approach to online cancer genetics education for Deaf American Sign Language users produces greater knowledge and confidence than English text only: A randomized study. Disabil Health J. 2017 Jan;10(1):23-32.

39 Sabatello M, Blake LA, Chao A, Silverman A, Ovadia Mazzoni R, Zhang Y, et al. Including the blind community in precision medicine research: findings from a national survey and recommendations. Genet Med. 2019 Nov; 21(11):2631-8
40 Sabatello M, Chen Y, Zhang Y, Appelbaum PS. Disability inclusion in precision medicine research: a first national survey. Genet Med. 2019 Oct;21(10):2319-27.

41 Silverman A. Healing the blind: perspectives of blind persons on methods to restore sight. In: Scott Robert J, Miller CA, Hays SA, Bennett I, editors. Nanotechnology, the brain and the future. Netherlands: Springer; 2013. pp. $159-66$.

42 Boudreault P, Baldwin EE, Fox M, Dutton L, Tullis L, Linden J, et al. Deaf adults' reasons for genetic testing depend on cultural affiliation: results from a prospective, longitudinal genetic counseling and testing study. J Deaf Stud Deaf Educ. 2010;15(3):209-27.

43 Kapp SK, Gillespie-Lynch K, Sherman LE, Hutman T. Deficit, difference, or both? Autism and neurodiversity. Dev Psychol. 2013 Jan;49(1):59-71.

44 Williams AS, Moore SM. Universal design of research: inclusion of persons with disabilities in mainstream biomedical studies. Sci Transl Med. 2011 May;3(82):82 cm12.

45 Rios D, Magasi S, Novak C, Harniss M. Conducting accessible research: including people with disabilities in public health, epidemiological, and outcomes studies. Am J Public Health. 2016 Dec;106(12):2137-44.

46 Sarfati D, Koczwara B, Jackson C. The impact of comorbidity on cancer and its treatment. CA Cancer J Clin. 2016 Jul;66(4):337-50.

$47 \mathrm{McDonald}$ KE, Keys CB. How the powerful decide: access to research participation by those at the margins. Am J Community Psychol. 2008 Sep;42(1-2):79-93.

48 Scherr CL, Ramesh S, Marshall-Fricker C, Perera MA. A Review of African Americans' beliefs and attitudes about genomic studies: opportunities for message design. Front Genet. 2019 Jun;10(548):548.

49 Sabatello M. Precision medicine, health disparities, and ethics: the case for disability in clusion. Genet Med. 2018 Apr;20(4):397-9.

50 Pellicano E, Dinsmore A, Charman T. What should autism research focus upon? Community views and priorities from the United Kingdom. Autism. 2014 Oct;18(7):756-70.

51 Kraft SA, Cho MK, Gillespie K, Halley M, Varsava N, Ormond KE, et al. Beyond consent: building trusting relationships with diverse populations in precision medicine research. Am J Bioeth. 2018 Apr;18(4):3-20.

52 Sabatello M. Cultivating inclusivity in precision medicine research: disability, diversity, and cultural competence. J Community Genet. 2019 Jul;10(3):363-73. 